\title{
LYMPHOGRAPHY AND THE UROLOGIST
}

\author{
R. G. MAHAFFY, F.R.C.S.E., F.F.R. \\ Department of Diagnostic Radiology, Royal Infirmary, Edinburgh.*
}

VARIOUS radiological methods of demonstrating lymph vessels and nodes have been utilised in the past. Interstitial injection of thorotrast (Menville and Ané, 1932), and contrast injection into lymph nodes (Bruun and Engeset, 1956), into body cavities (Bennet and Shivas, 1954) and into joint spaces have all resulted in some degree of visualisation of a limited segment of the lymphatic system. Detailed study of the pelvic and abdominal lymph nodes, however, was not possible until Kinmonth (1952) described a practical method of intralymphatic injection. He used a water soluble contrast medium to demonstrate the lymph vessels of the legs in cases of lymphoedema. Such media, however, rapidly diffuse out of the lymphatics and for this reason are not suitable for investigation of retroperitoneal lymph nodes. Oily media are necessary for this purpose and have become standard for lymphography (Wallace, Jackson, Schaffer, Gould, Greening, Weiss and Kramer, 1961; Rüttimann and Del Buono, 1962).

\section{Technique}

The technique of lymphography is now well known and requires no detailed description. Briefly, lymphatics on the dorsum of the foot are rendered visible by a subcutaneous injection of a dye such as patent blue violet. Under local anæsthesia a vessel is exposed and, by proximal obstruction and manipulation of the toes, distended to its maximum diameter. The vessel may then be catheterised or a needle introduced. I have found catheterisation to be simpler and much more stable, allowing fairly free movement of the foot during the injection. A minute incision is made in the vessel, a polythene catheter (No. 45, Portland Plastics) introduced, the vessel ligated round the catheter and the catheter sutured to the skin edge. For visualisation of retroperitoneal nodes the procedure must be repeated on the other foot. Warmed ultra-fluid lipiodol is then injected bilaterally, simultaneously, at a very slow speed. I have found $7.8 \mathrm{ml}$. lipiodol in each leg to be

\section{* Present Address:}

$X$-ray Department, Royal Infirmary, Aberdeen. adequate in most cases, unless visualisation of the thoracic duct is required when larger amounts will be necessary. The procedure should be controlled by means of an image intensifier and the injection stopped if any evidence of lymphatic obstruction is seen. At the termination of the injection a series of films of the pelvic and lumbar regions is taken. These must include oblique and lateral views in order to throw the vessels off the underlying bone and avoid superimposition of lymphatic structures. In this series the lymph vessels are well shown but the nodes are only partially filled with contrast. It is noteworthy that initially the lipiodol will flow from afferent to efferent lymphatics, via the marginal sinus of the node, with no filling whatever of the remaining nodal sinuses. 24 hours later the series is repeated, when the nodes should be well filled with contrast and the vessels entirely empty. Multiple projections are important at this time to show all surfaces of the nodes.

Lipiodol remains in the nodes for 4-6 months and subsequent changes can be followed on plain films.

\section{Lymphatic Anatomy}

One of the major contributions of lymphography has been the demonstration of normal lymphatic anatomy (Herman, Benninghoff, Nelson and Mellins, 1963). Two systems of lymphatics occur in the leg, one accompanying the long saphenous vein and the other the short. Injection of a long saphenous lymphatic at the foot results in visualisation of up to 20 vessels in the thigh, which drain into superficial inguinal lymph nodes. Short saphenous lymphatics drain into a separate group of superficial inguinal nodes, and there appears to be no communication between these systems in the leg (Jacobsson and Johansson, 1959). About a dozen nodes are seen in the superficial inguinal region and these are arranged in a rather haphazard manner, although two groups can be recognised, one lying transversely below the inguinal ligament and the other distal to this and parallel to the long axis of the limb. 


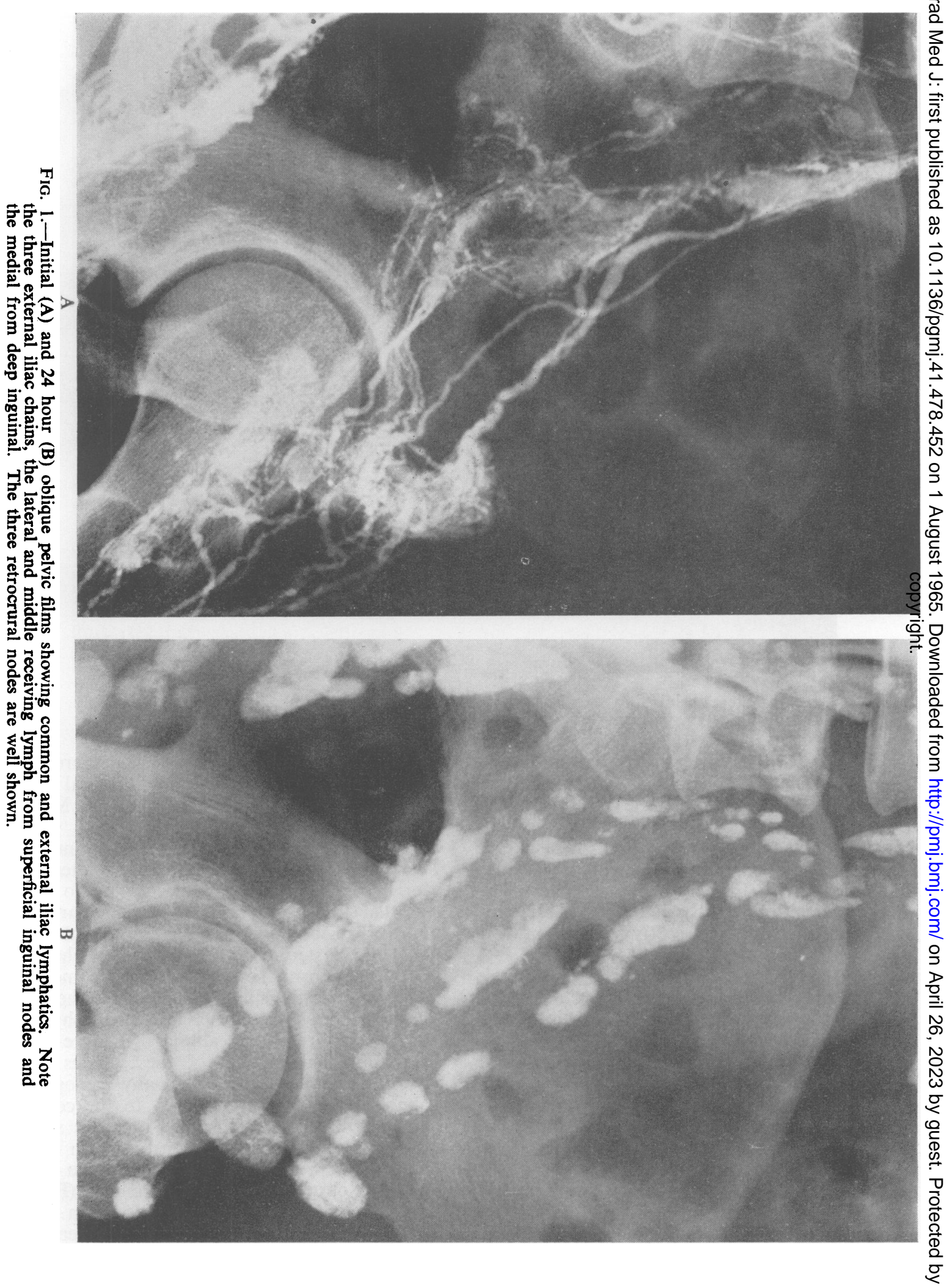




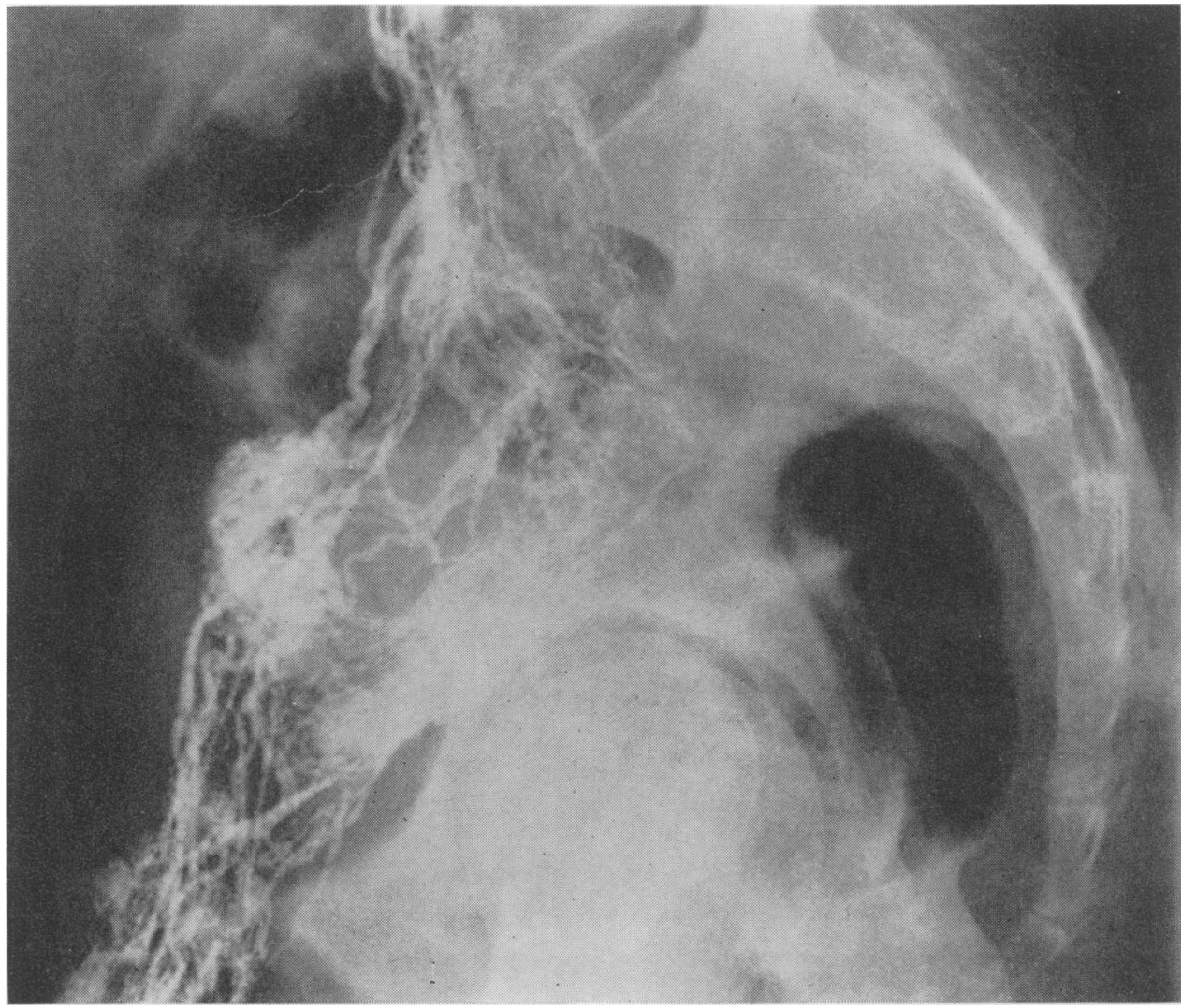

FIG. 2.-Lateral pelvis film showing the medial external iliac lymphatic chain dipping deeply into the pelvis, particularly in the internal iliac region.

The external iliac system is divided into three chains. A lateral chain lies lateral to the external iliac artery, a middle one medial to the artery and a medial chain behind the vein on the lateral pelvic wall (Fig. 1). In a lateral view the medial chain can be seen to dip deeply into the pelvis (Fig. 2). The superficial inguinal nodes drain partly directly to the lateral and middle chains and partly via one or two deep inguinal nodes to the medial chain. At the distal ends of these chains lie the lateral, middle and medial retrocrural nodes, which are fairly large and constant. There is a very free communication between the chains by means of multiple, transversely arranged vessels. Proximal to the medial retrocrural node lies the 'middle' or 'principle' node which is large and constant and communicates with the obturator nodes, which as a rule are filled by lymphography carried out from the foot.

Owing to the valved nature of lymph vessels retrograde flow does not normally occur. As a result the internal iliac system is not filled in its entirety although a few nodes are often $\frac{\overrightarrow{0}}{3}$ seen, particularly in the lateral sacral group (Herman, Benninghoff, Nelson and Mellins, 1963).

The three external iliac chains continue into $\frac{\overline{3}}{3}$ the common iliac region, but there is a tendency for the medial and middle chains to unite, so that frequently only two chains are seen 8 in this region, one anterolateral to the vein and one posteromedial. The medial chains of 0 both sides form the nodes of the promontory. $\rightarrow$ The close relationship of the nodes to the pelvic veins is the basis of pelvic venography as a diagnostic procedure, although $I$ have found $\%$ surprising enlargement of these nodes to be $\stackrel{N}{\circ}$ possible without producing any venographic: abnormality (Mahaffy, 1964). In the commoto and internal iliac regions the ureter is seen too come into intimate relationship with lymph nodes, enlargement of which may give rise to $\stackrel{?}{+}$ ureteric obstruction or displacement (Fig. 3). Tㅜㅜ The common iliac lymphatics drain into $a \frac{0}{D}$

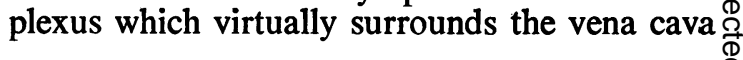




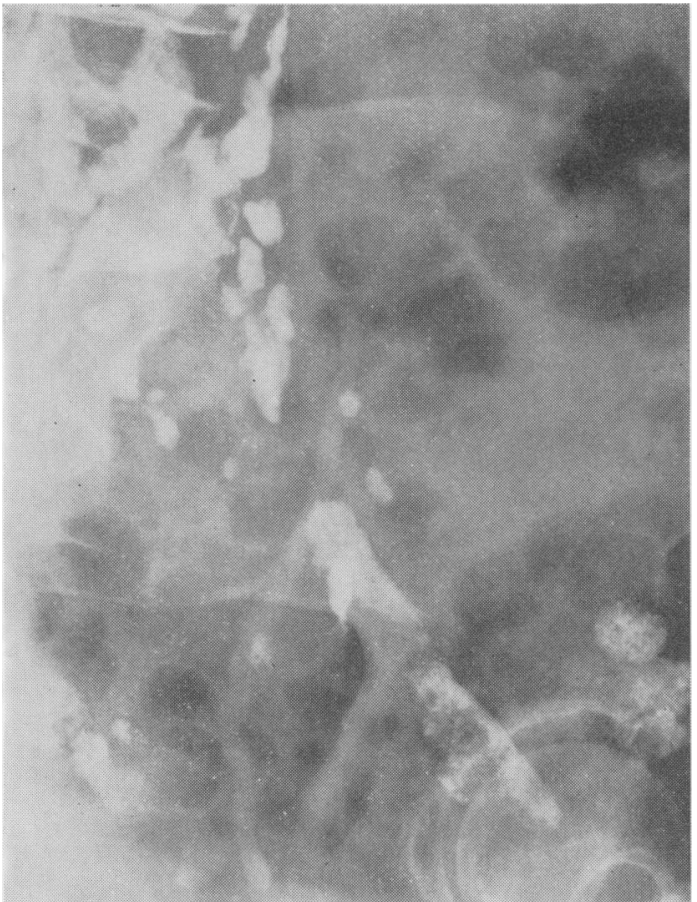

FIG. 3.-Oblique film of the pelvis showing the relationship of the ureter to the pelvic lymph nodes.

and aorta and is divided into four groups. The right latero-aortic group lies on all sides of the vena cava, but only one or two nodes are anterior to it and these occur only at its lower end. The left latero-aortic, pre-and retro-aortic groups lie to the left, in front of and behind the aorta. Good filling of contralateral para-aortic lymphatics is normally obtained when unilateral lymphography is carried out, and an almost constant crossing vessel is seen at the first sacral level. At the level of the second lumbar vertebra the paraaortic vessels drain into the cisterna chyli and if sufficient contrast is injected the entire thoracic duct may be visualised. Only rarely are mediastinal nodes demonstrated but left supraclavicular nodes are frequently seen. By obstructing the termination of the thoracic duct by means of pressure in the left supraclavicular fossa, Seitzman and Halaby (1964) were able to fill axillary and mediastinal nodes.

Extensive collateral pathways exist which are not visualised, and possibly not utilised, unless lymphatic obstruction is present. Such channels may give rise to metastatic deposits in bizarre situations, particularly where the main lymph pathways are obstructed by tumour.

\section{Complications and Precautions}

A number of patients suffer from a mild fever for 24-48 hours following lymphography. These patients are generally symptom-free and recover spontaneously. In a small number of cases, however, serious reactions have occured and Desprez-Curely, Bismuth, Laugier and Descamps (1962) report one fatality. Many patients have visible lipiodol in the lung-fields following the injection and, although I have not found reactions to be proportional to the degree of pulmonary lipiodol embolism, nevertheless it must be advisable to limit the amount of contrast reaching the blood stream. For this reason the volume of contrast injected should be restricted to the minimum consistent with good radiographic detail of the lymphatic system. I stop the injection when the contrast reaches the mid-lumbar region, since I find that subsequently good filling of the upper lumbar nodes occurs by onward passage of lipiodol in the vessels at the end of the injection, and that only minimal amounts pass beyond the diaphragm.

It is also necessary to follow the course of the lipiodol so that lymphatic obstruction at any level may be recognised at an early stage. If evidence of this is seen the injection must be stopped since lymphatic-venous communications may open up distal to such an obstruction, allowing lipiodol to pass directly into the blood stream (Bron, Baum and Abrams, 1963).

It is necessary to $\mathrm{X}$-ray the chest prior to lymphography and restrict the procedure to those patients whose lung-fields are clear, since pulmonary pathology of any kind tends to increase the effect of lipiodol embolism.

Following radiotherapy to the abdomen or pelvis there is a reduction in the number and size of lymph nodes, and these retain less contrast than normal, allowing larger amounts to pass beyond the diaphragm and enter the blood stream. Caution is necessary in these patients, therefore, and the volume injected should be reduced.

Lipiodol gives rise to a lipogranulomatous reaction in the nodes, characterised by large giant cells. These reactions reach their peak in 2-3 days but thereafter subside and the node finally returns to normal. No fibrotic or other permanent change occurs in the node and repeat lymphograms will demonstrate no evidence of lymphatic obstruction or other abnormality attributable to the initial lymphogram. 

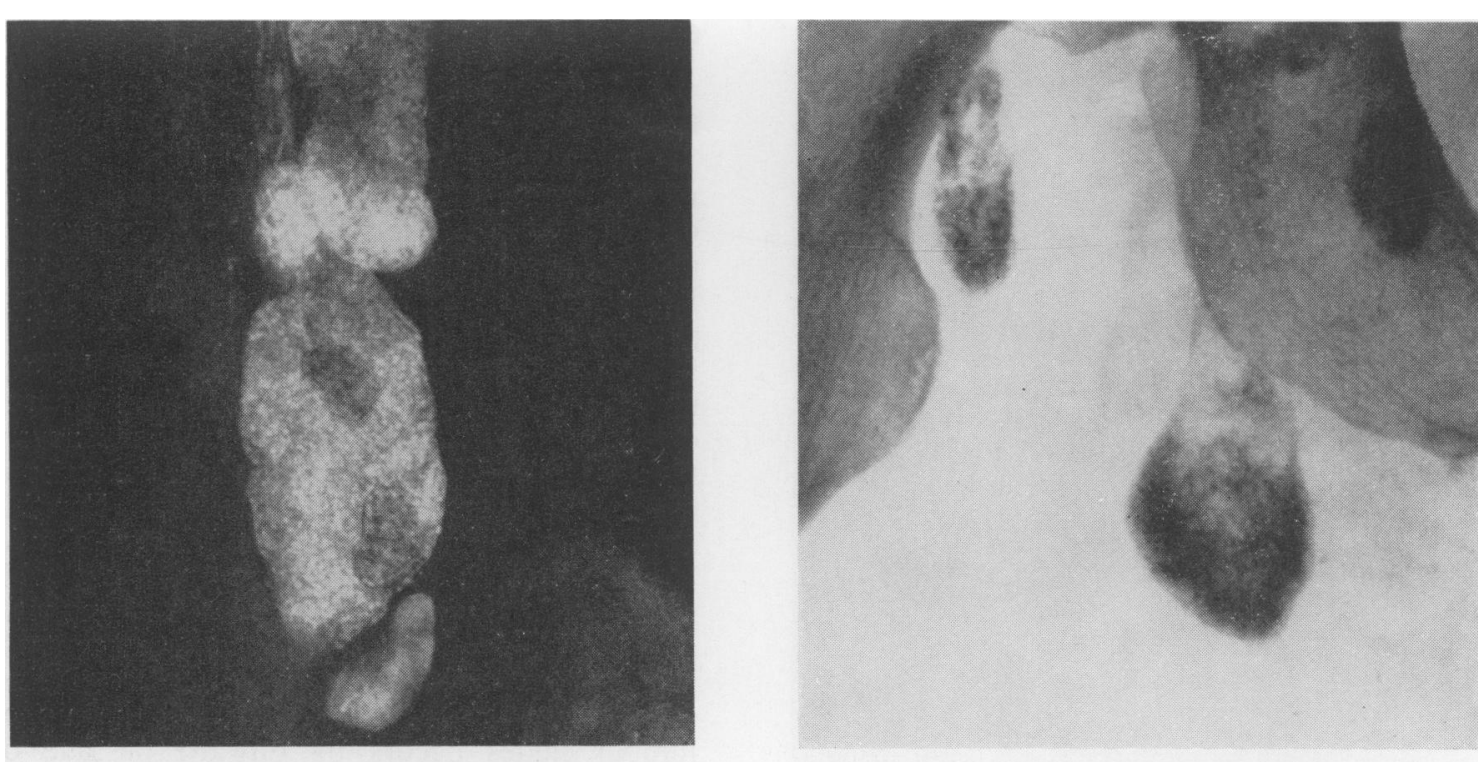

A

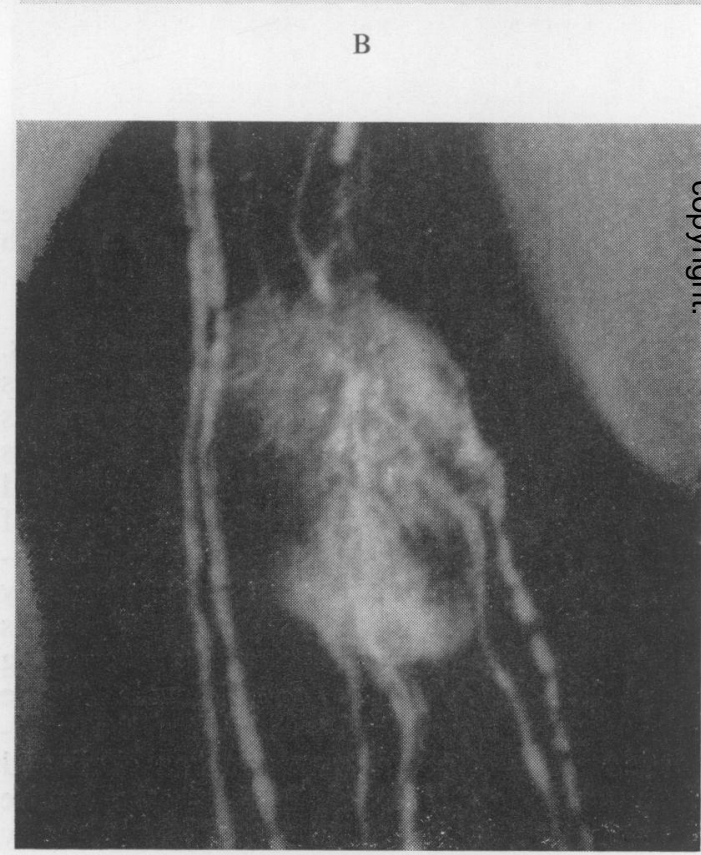

$\mathrm{D}$

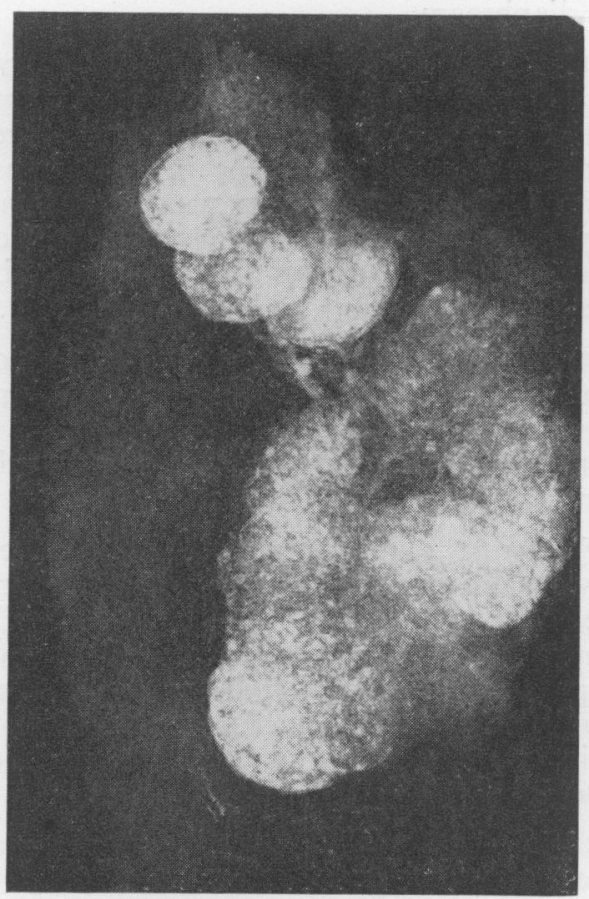

C

FIG. 4.- (A) Excised lymph node following lymphography. Note the two clearly defined central filling defects due to areas of fatty degeneration. (B) Superficial inguinal lymph node showing ill-defined defect at the proximal pole, due to the hilum. (C) Excised group of small nodes. A clearly defined, triangular filling defect is formed by the superimposed margins of the nodes. (D) Superficial inguinal lymph node showing two ill-defined filling defects due to recurrent inflammatory changes. 


\section{The Pathological Node}

Following lymphography the normal lymph node shows an even distribution of contrast droplets throughout the nodal sinuses, the marginal sinuses giving the node a clearly defined contour. Its size varies widely and it may measure as much as $3 \mathrm{~cm}$. in its long diameter. Malignant cells enter the node by afferent channels to reach the marginal sinus where they may be arrested and metastases formed. In the early stages, therefore, a metastatic deposit appears as a peripheral filling defect, usually with an irregular margin. The accuracy of lymphography in detecting metastases varies with the size of the deposit. In the early stages, when a node is not enlarged and is only partially replaced by tumour tissue, an accurate diagnosis cannot be made with confidence (Kendall, Arthur and Patey, 1963). Similar filling defects may: be produced by a variety of non-malignant conditions. Areas of fibrosis or fatty degeneration usually produce clearly defined, central filling defects (Fig. 4,A) but may cause peripheral defects indistinguishable from metastatic deposits. The hilum normally appears as a clearly defined impression at the proximal pole of the node, but on occasion may show as an ill-defined filling defect (Fig. 4,B). As a rule the position of the hilum can be identified on the initial film showing the contrast filled afferent and efferent vessels, but this is not always so. The margins of partially superimposed nodes may give an appearance similar to a filling defect (Fig. 4,C). The lymph follicles may produce defects up to $3 \mathrm{~mm}$. in diameter. Inguinal and external iliac nodes, in particular, may show incomplete filling due to recurrent inflammatory changes, secondary to repeated lower limb infections (Fig. 4,D). The diagnosis of small metastatic deposits at this stage is not, therefore, possible. With enlargement of the deposit, however, a reaction occurs in the remainder of the node resulting in an increase in size. Baum, Bron, Wexler and Abrams (1963) suggest that a positive diagnosis can be made if the node is enlarged and the deposit occupies not less than $25 \%$ of the node. Unfortunately, nodes vary in size to such an extent that it is often difficult to say whether they are enlarged or not, and, in addition, non-malignant conditions may result in non-filling of $25 \%$ of the node or more.

At a later stage there is complete replacement of the node by malignant tissue. The node is then not visualised at all and, since the distribution of nodes is neither constant nor

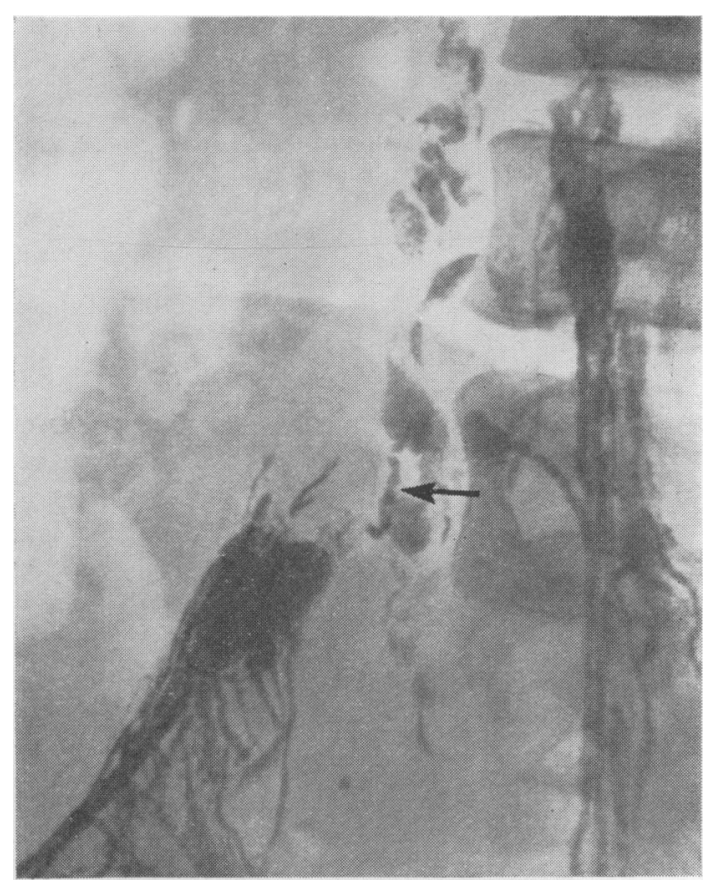

FIG. 5.-Lymphogram of patient with right testis tumour. There is evidence of lymphatic obstruction at the level of L.V.5, due to a metastatic deposit. A dilated collateral channel is seen (Arrow).

symmetrical, the lymphographic appearances may not be abnormal. At this stage, however, the deposit frequently gives rise to evidence of lymphatic obstruction (Fig. 5). This appears as irregularity or sudden alteration in the course of lymph vessels (Fig. 6), retention of contrast within the vessels in the 24 -hour film, evidence of dermal backflow and the presence of collateral channels. Dilatation has not been found to be a significant feature, since wide, beaded lymphatics are frequently seen in the absence of obstruction. At this stage, therefore, a diagnosis of metastatic deposit can often be made by an evaluation of indirect signs, and the accuracy of diagnosis will largely depend on the experience of the observer. Close scrutiny of the initial films, taken at the termination of the injection, is essential, since these are frequently more helpful than the 24-hour films, showing only the nodes (Fig. 6).

With further enlargement a metastatic mass is formed, and at this stage lymphography is a highly accurate procedure. In addition to the indirect signs of lymphatic obstruction there is frequently contrast filling of irregular, abnormal lymph spaces within the mass (Fig. 7), and outlining of part of the periphery is a common 
August, 1965

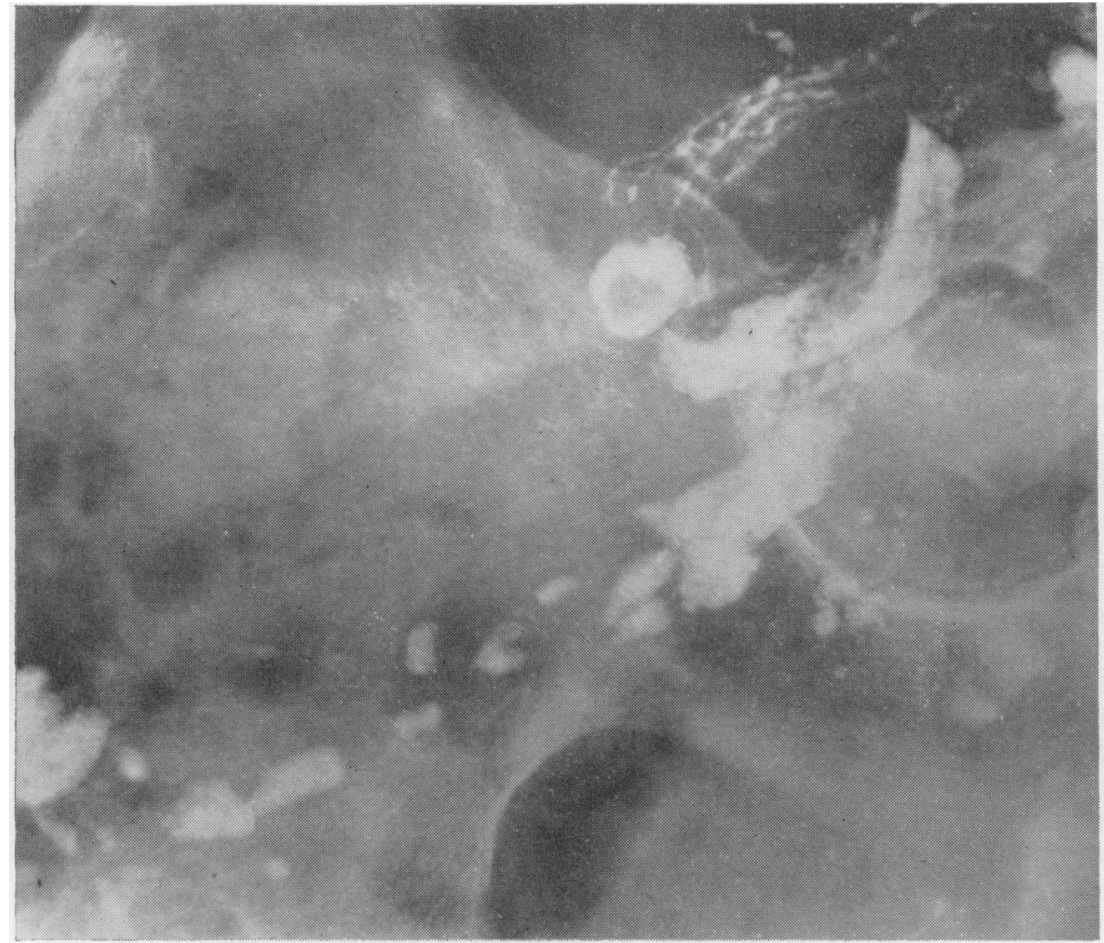

管焉

$\infty$ 这 탠웡 폴. 음 丞 胥. 5ี $x \cdot \frac{0}{\circ}$

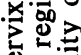
\& 을

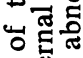
范苍.气

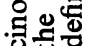
ฮึ. 음

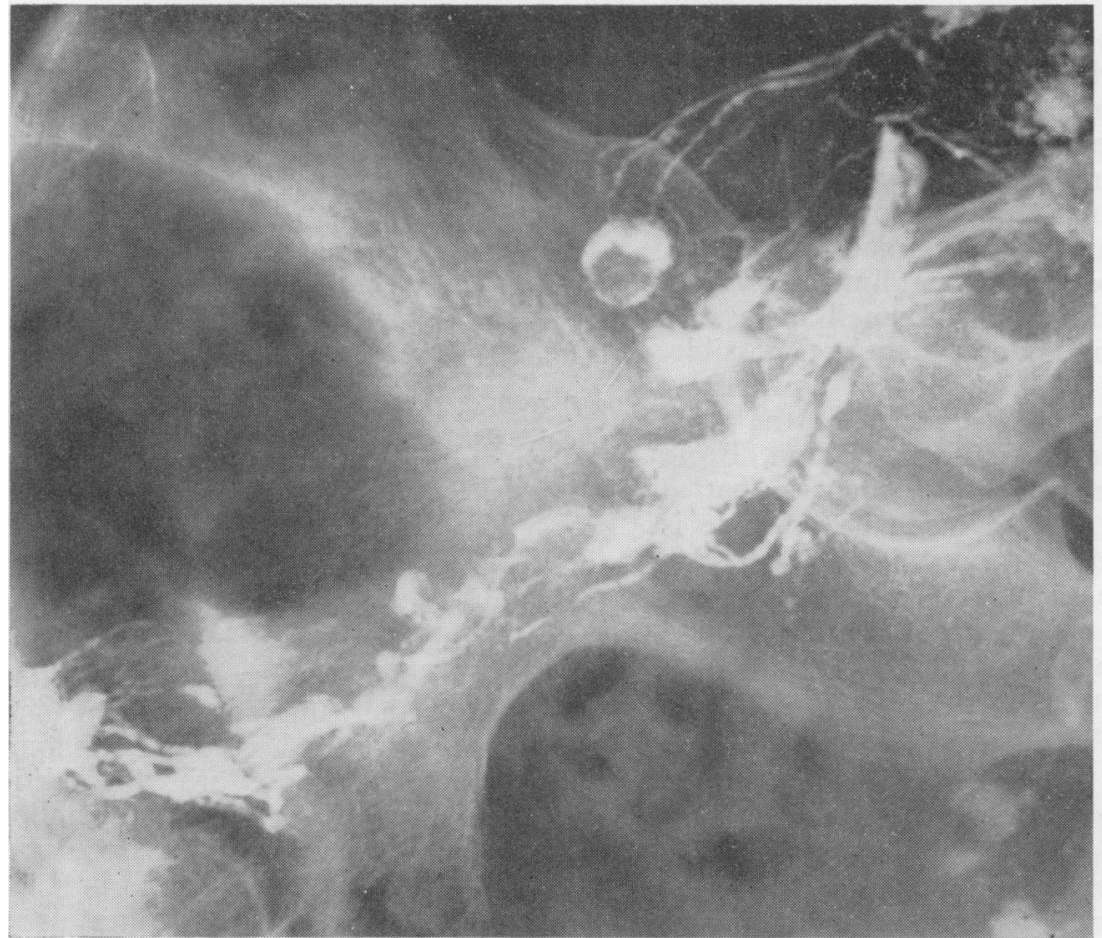


finding (Fig. 12). No normal nodes are demonstrated in the region of the mass. Rarely, I have seen a mass containing a fine meshwork of contrast filled channels (FIG. 9A).

It should be appreciated that retroperitoneal metastases, up to the stage when there is complete replacement of the node, are rarely detectable by clinical examination or by other radiological methods and that lymphography at least offers a possibility of their recognition, although negative findings have, of course, little significance. In my own experience, lymphography has on a number of occasions demonstrated clinically unsuspected metastases in tumours of testis, bladder and cervix, and I do not agree with Koehler, Meyers, Skelley and Schaffer (1964) who consider that lymphography rarely shows deposits which are not suspected on physical examination. Even metastatic masses may reach a surprising size without being clinically palpable, and the same is true of lymphomatous nodes.

The lymphographic appearances in the reticuloses are characteristic. They produce enlarged lymph nodes with an open, lacy pattern and, in the early stages, a very clearly defined, intact outline. With enlargement of the affected nodes the pattern becomes faint and ghost-like and begins to disintegrate. As a rule the reticuloses are not associated with any evidence of lymphatic obstruction. On occasion, Hodgkin's disease may be differentiated since, in addition to the above features, the nodes may contain irregular, central filling defects. It is said that chronic lymphatic leukæmia may be associated with irregular, central pools of contrast, within the background pattern described above. Rarely, seminoma metastases may have a similar lacy pattern (Whitesel, 1964), and further possible sources of error are rheumatoid arthritis and sarcoidosis, both of which may be associated with a diffuse lymphadenopathy and a reticular nodal pattern. Nevertheless, lymphography has a high degree of accuracy in detecting nodes involved by a reticulosis.

Acute inflammation also gives rise to lymph node enlargement but the normal internal pattern is usually retained. On occasion, however, peripheral defects may occur giving rise to confusion with metastatic deposits (Fig. 8).

\section{Clinical Applications}

\section{Testis Tumours}

Contrast injections into lymph vessels in the spermatic cord have confirmed Rouvière's (1932) classic description of the lymphatic

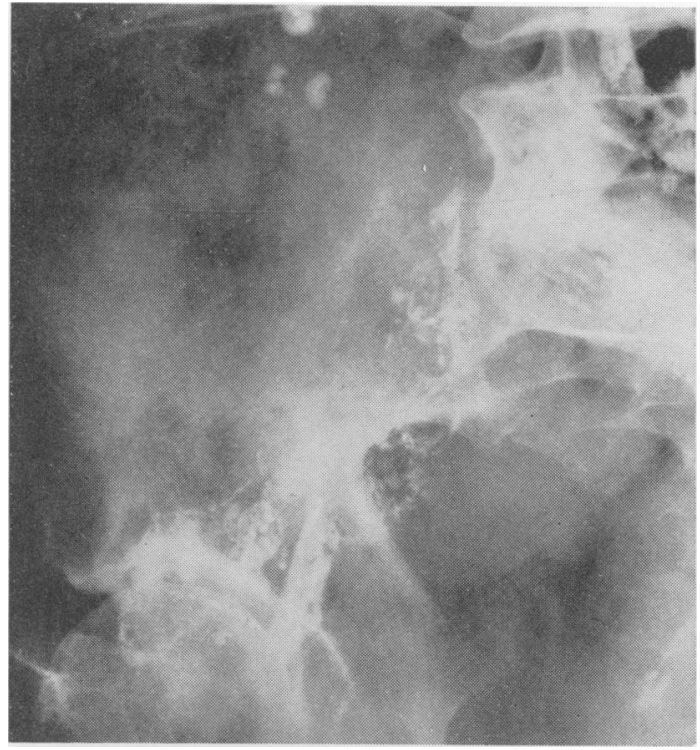

FIG. 7.-Right oblique pelvis film of patient with carcinoma of the cervix. There is contrast filling of multiple, irregular, abnormal lymph spaces within a metastatic mass.

drainage of the testis. Lymph vessels accompany the spermatic vessels and drain into paraaortic nodes from the level of the renal veins to the bifurcation of the aorta. A further vessel diverges to reach an external iliac node. In addition, tumours which transgress the tunica albuginea may metastasise to inguinal nodes. All of these nodes are visualised by lymphography carried out from the foot. Lymphography has also demonstrated that lymph drainage from a testis is also to the contralateral para-aortic nodes.

In this country it is almost universal practice to treat testis tumours by orchidectomy followed by supervoltage radiotherapy to the para-aortic nodes and to pelvic nodes on the side of the tumour (Smithers and Wallace, 1962). Results with this technique have been excellent for seminomas but not quite so good for teratomas. Elsewhere, retroperitoneal lymphadenectomy, usually with subsequent radiotherapy, has been favoured by many for teratomas (Tavel, Osius, Parker, Goodfriend, McGonigle, Jassie, Simmons, Tobenkin and Schulte, 1963) and by some for all tumours. There is little doubt that radical surgery is unnecessary for seminomas and for the majority of teratomas, but it has probably a place in the management of those teratomas which are relatively radioresistant. Whichever form of treatment is preferred lymphography is of 


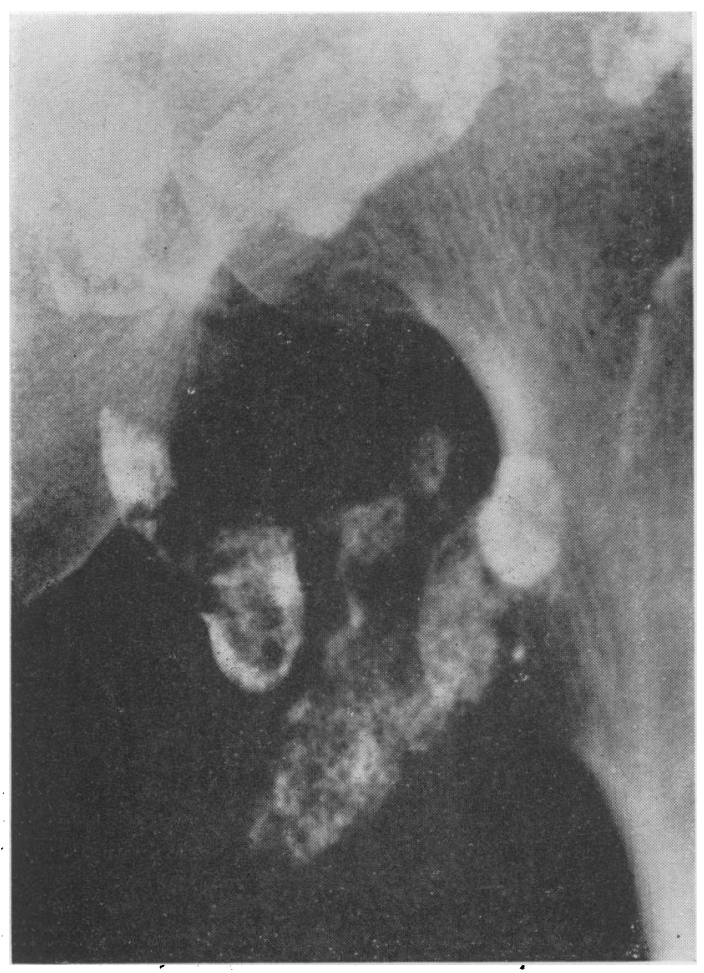

Fig. 8.-Enlarged superficial inguinal lymph nodes due to an acute inflammatory reaction. Irregular filling defects are shown in the absence of metastatic deposits.

considerable value. To the radiotherapist it offers a means of reducing to a minimum the volume of tissue irradiated while at the same time ensuring that all relevant lymph nodes are treated. Such restriction of the size of the field is essential, even with supervoltage radiotherapy, to avoid damage to other tissues, particularly the kidneys. When a nodal metastasis or metastatic mass is demonstrated additional, strictly localised radiation may be delivered to it. Delineation of the outline of a mass is, therefore, of great importance and it must be admitted that in this respect lymphography may be disappointing. It will show the presence and site of the lesion but will frequently fail to demonstrate its exact extent. In the right para-aortic region cavography may give valuable information regarding the size of a mass, particularly if it arises from retrocaval nodes, although left-sided lesions may reach a very large size without producing any effect whatever on the vena cava (Mahaffy, 1964) (Fig. 9). In addition, urography may

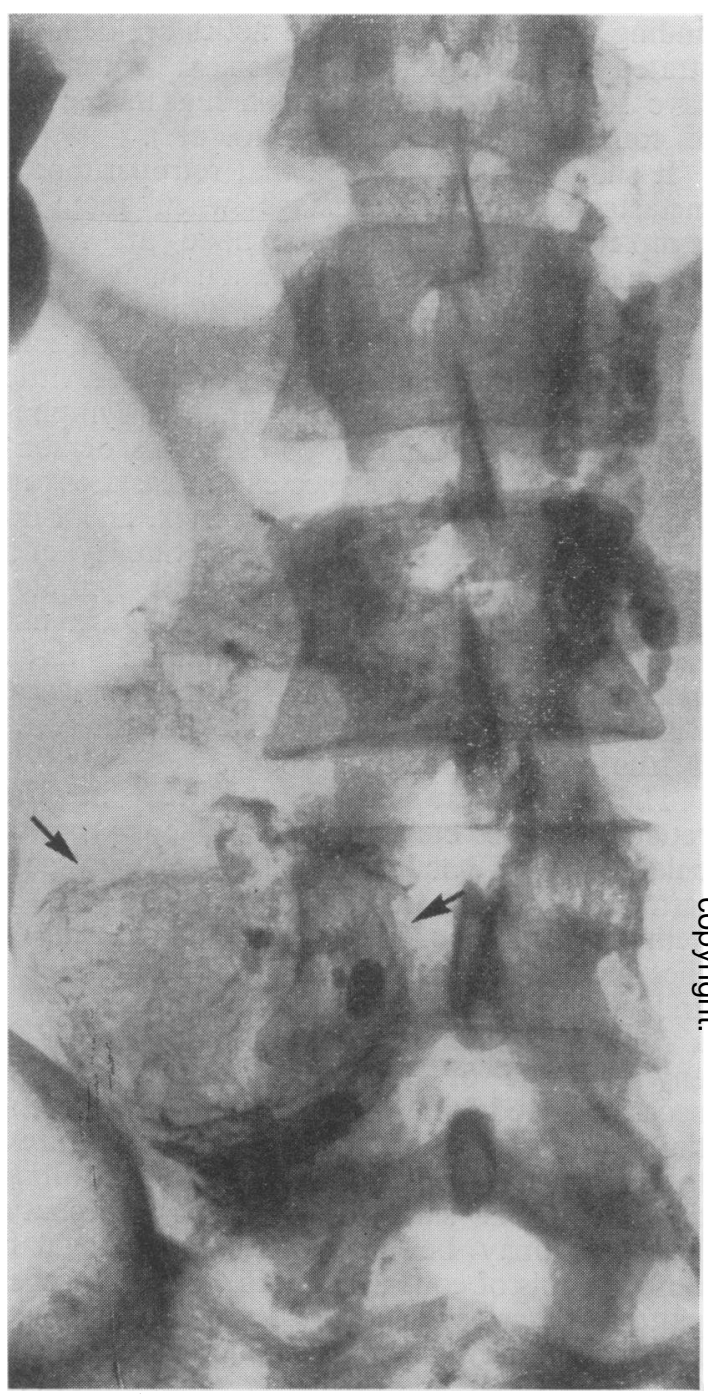

Fig. 9A

help in demonstrating the lateral extent of a mass by showing displacement of the ureter. In such cases, therefore, these three procedures are complementary and all should be carried out (Fig. 10). Contrast remains within the lymph nodes for several months following lymphography and the response of a mass to radiotherapy can, therefore, be assessed from subsequent plain films (Fig. 11). A further advantage of lymphography is that it may indicate the necessity for mediastinal and supraclavicular therapy, which would not otherwise have been given, by demonstrating clinically unsuspected para-aortic metastases. 


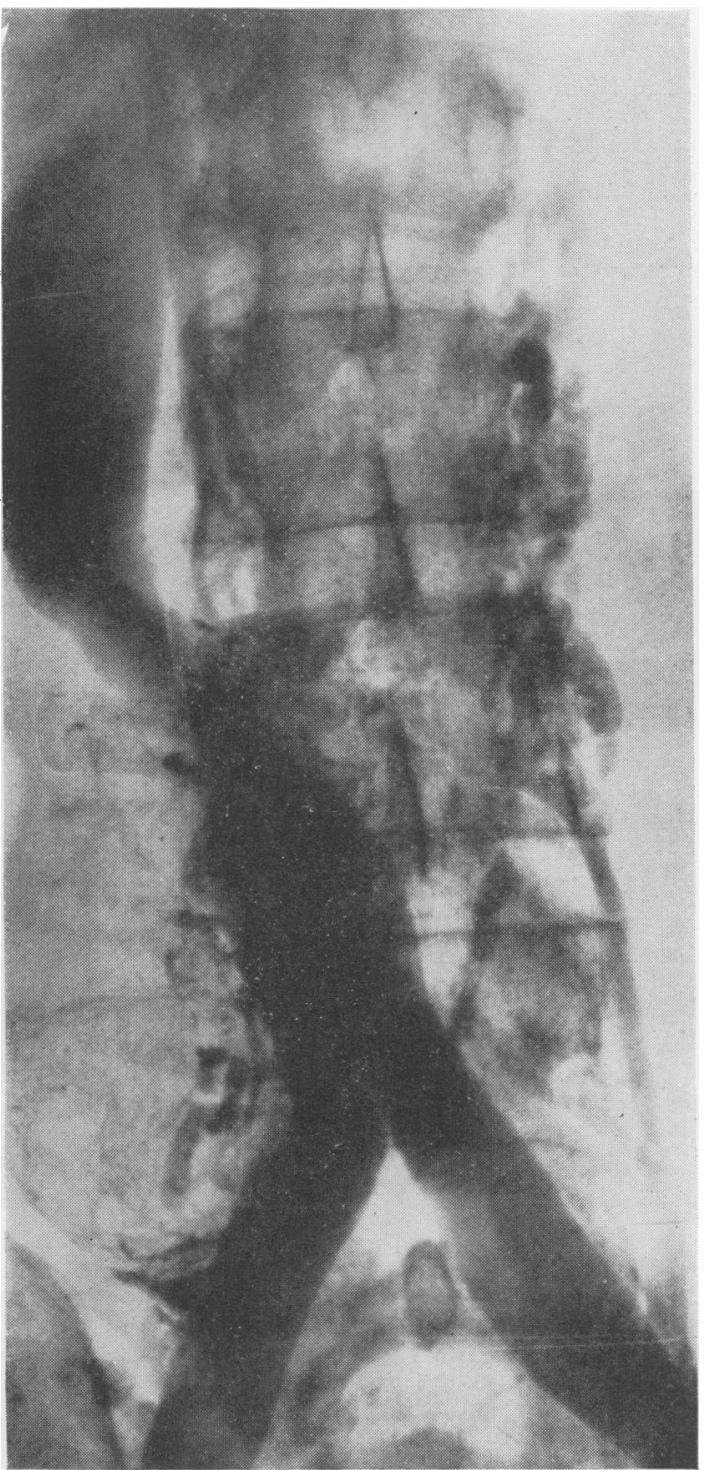

FIG. 9B

Where radical surgery has been preferred lymphography has proved to be of great value as an aid to total extirpation of retroperitoneal nodes. One of the arguments against lymphadenectomy has been the impossibility of achieving complete removal of all nodes, the retrocaval and renal regions being the most difficult to dissect. Even in cadavers, Tavel and his associates (1963) failed to remove all paraaortic nodes. Following lymphography, however, with the aid of image intensification or radiography in the operating theatre, total

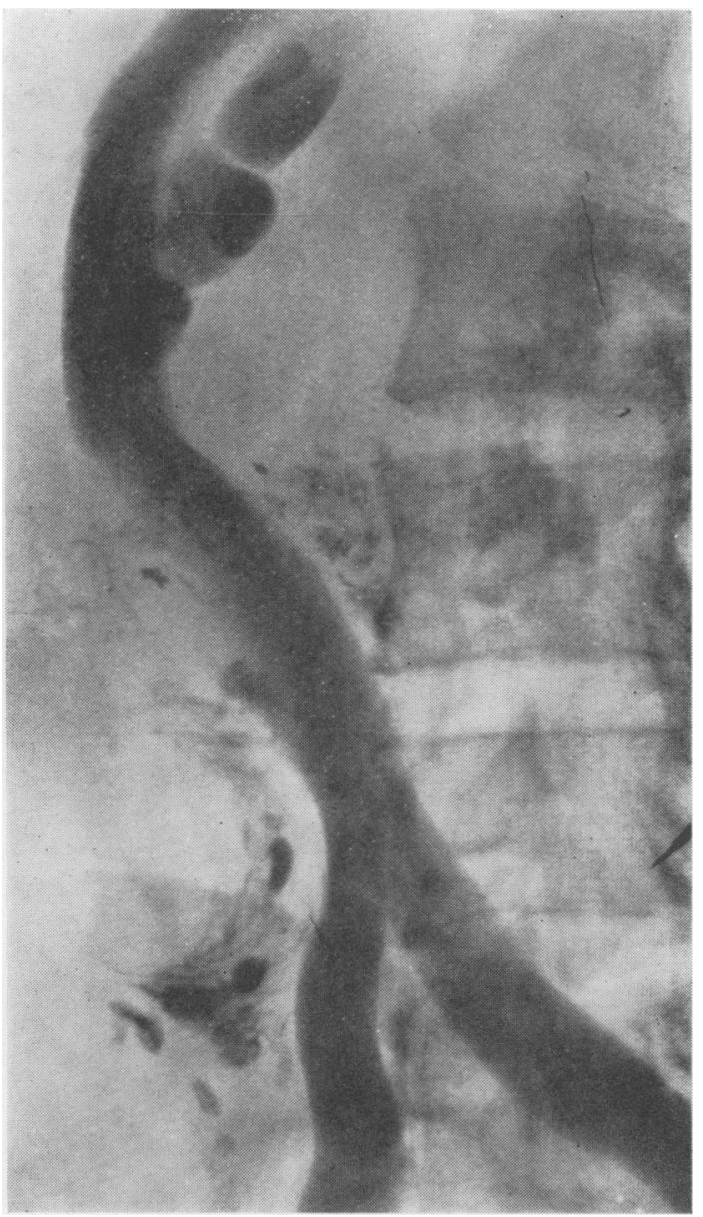

Fig. 9C

FIG. 9.-Right testis tumour. The lymphogram (A) shows a large, rounded metastatic mass at the level of L.V.4 (Arrows), containing a fine meshwork of lymphatic channels. Above this there are multiple, irregular, contrast filled spaces with no normal nodes seen, indicating a further mass. $A$ cavogram ( $B$ and $C$ ) shows the lower mass to lie anterior to the vena cava and to produce little impression on the vein. The upper mass lies posteriorly and produces very marked displacement. The cavogram gives a much more accurate estimate of the extent of the posterior mass than does the lymphogram.

lymphadenectomy is now possible. The addition of chlorophyll to lipiodol is also of assistance to the surgeon, since by this method the nodes are coloured green and are readily visible, although there is a tendency for the nodes closer to the site of injection to take up more dye than those more distal. Where surgical treatment is indicated lymphography 


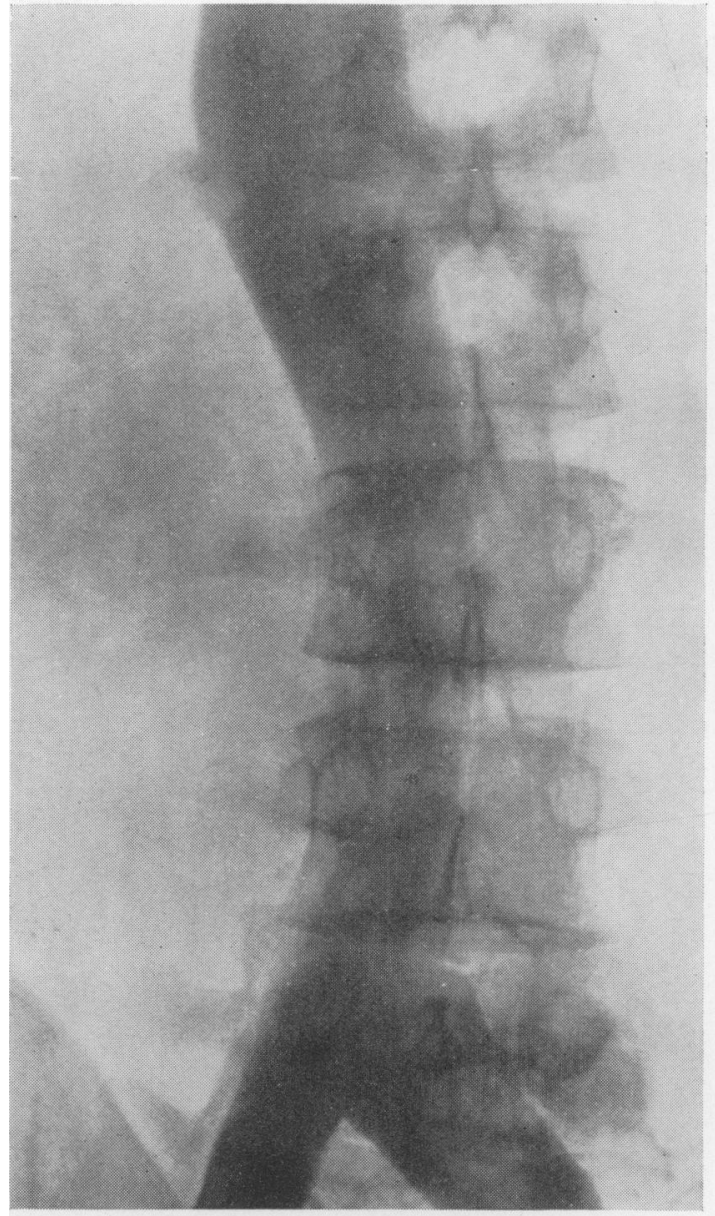

FIG. 10A

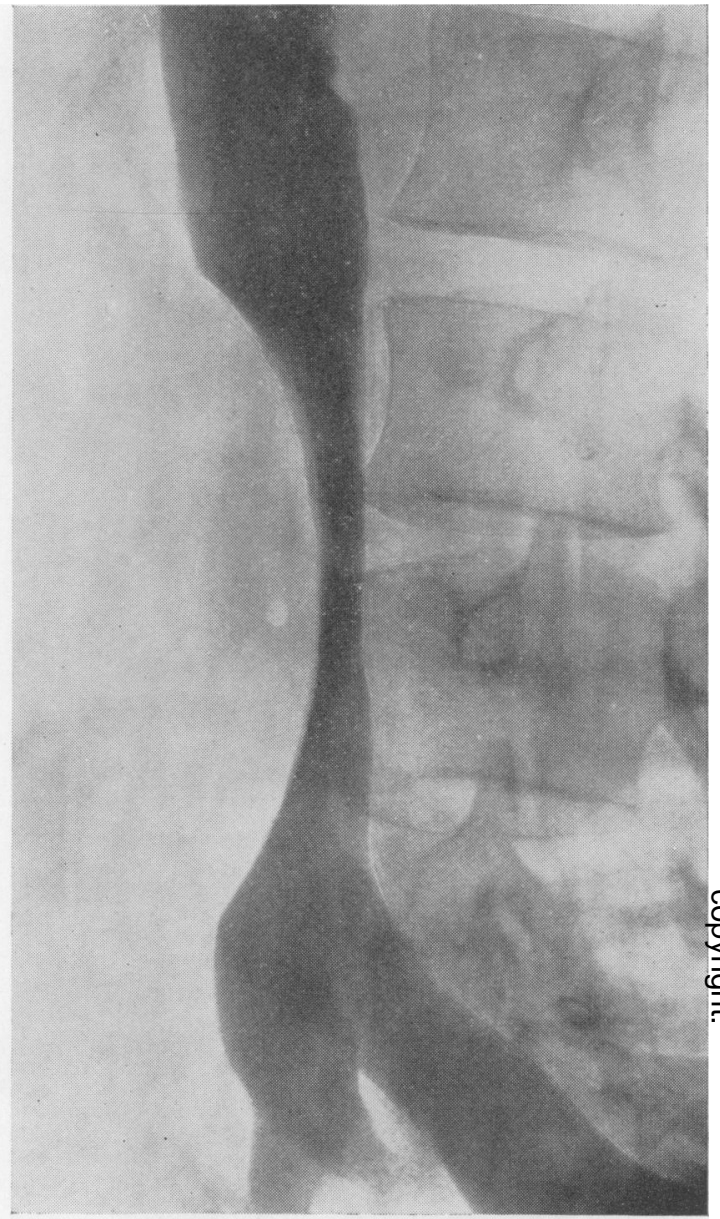

FIG. 10B

Fig. 10.-Right testis tumour. The cavogram (A and B) shows a large mass anterior and to the right of the inferior vena cava. The lymphogram ( $C$ and $D)$ shows evidence of lymphatic obstruction at the level of L.V.5, with filling of very few right para-aortic nodes above this, indicating the presence of a metastatic mass but giving no idea of its extent. The urogram (C and D) shows displacement of the ureter, indicating the lateral extent of the mass. In this case all three procedures contributed to an accurate assessment of the lesion.

has clearly demonstrated the necessity for bilateral lymphadenectomy.

Macdonald and Wallace (1965) describe a further application of lymphography to testis tumours. In patients who present with supraclavicular node metastases from a seminoma or teratoma, with clinically normal testes, a lymphogram may demonstrate para-aortic node deposits, indicating that the primary is, in fact, testicular and not mediastinal.

\section{Renal Tumours}

Lymphatic drainage from the kidneys is largely to the para-aortic nodes at the level of the hilum, although the posterior aspect of the upper pole may drain through the diaphragm to the lower posterior mediastinal nodes. Metastases in the para-aortic nodes are not uncommon and may be demonstrated by lymphography. Robson (1963) reported a $22.5 \%$ incidence of regional node metastases in renal cell carcinoma. He advocates a radical nephrectomy, which includes block dissection of para-aortic nodes, and with this technique claims to have improved survival figures. For the best results. however. such dissection would 


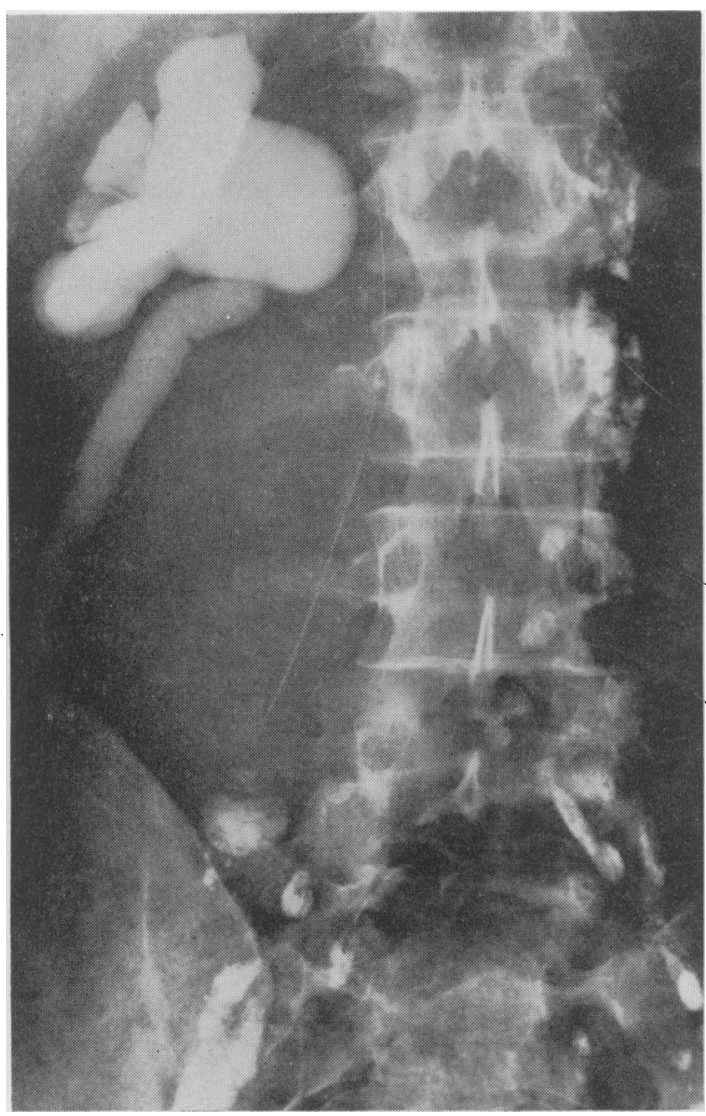

Fig. 10C

have to be bilateral. Lymphography may aid in selection of patients for radical operation and will assist in achieving complete lymphadenectomy.

\section{Bladder Tumours}

The lymphatic drainage of the bladder is in three directions; from the superior and inferolateral surfaces to the external iliac nodes (Fig. 12); from the base largely to the external iliac but also to the internal iliac nodes; from the neck to the internal and common iliac nodes (Fig. 13). It is one of the disadvantages of lymphography carried out from the foot that the internal iliac chain is not demonstrated in its entirety, although several of these nodes are frequently seen. Radiological detection of internal iliac metastases may be achieved in some cases by urography (Fig. 14) or pelvic venography, although the sensitivity of these procedures is not high. However, the internal

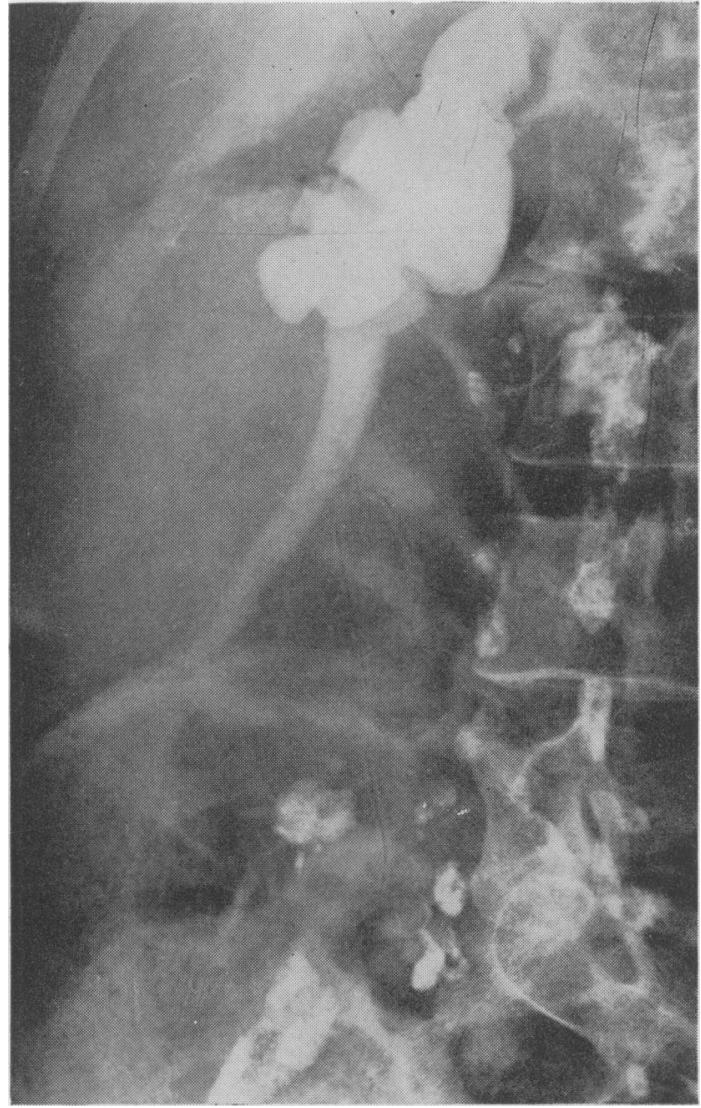

Fig. 10D

iliac chain is of relatively minor importance in the lymphatic drainage of pelvic organs (Herman and others, 1963).

The choice of treatment for each stage and grade of bladder tumour is largely a matter of personal preference. Uniformly good results are obtained with early stage and low-grade tumours but the wide variety of techniques advocated for invasive tumours reflects the poor results obtained in these cases. Whitmore and Marshall (1962) use radical cystectomy as a curative procedure and include pelvic lymphadenectomy from the mid-common-iliac region to the inguinal ligament. The lymphographic detection of more than two metastases rules out the possibility of cure in their opinion and palliative treatment only is given. Again, lymphography will assist the surgeon during pelvic node dissection and will also contribute information of value in accurately staging tumours and, therefore, in assessing the effectiveness of treatment. 


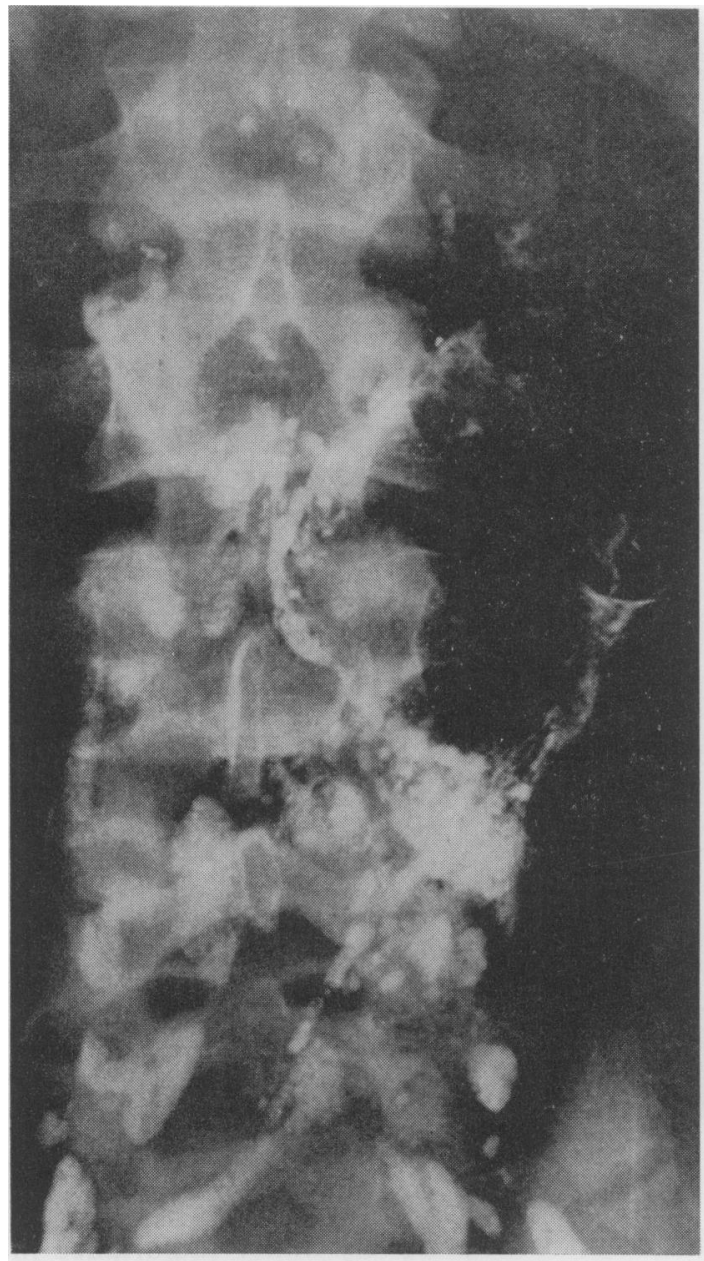

A

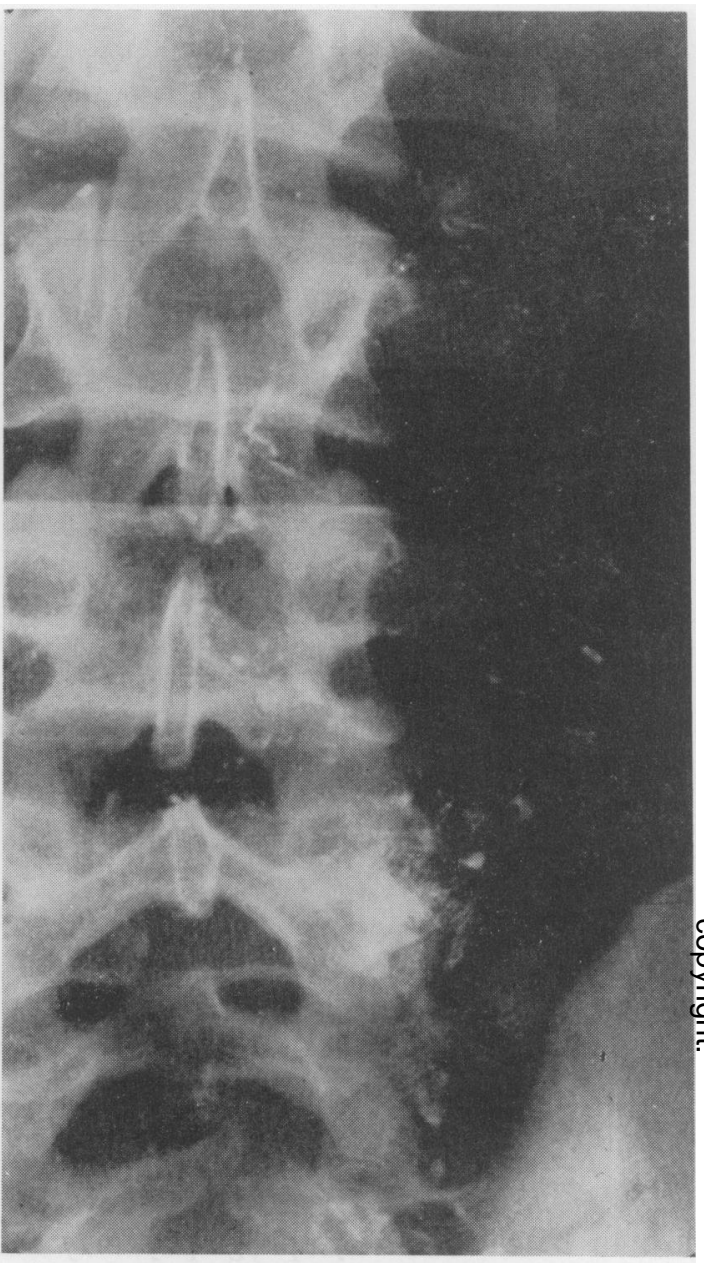

B

FIG. 11.-Left testis tumour. The lymphogram shows an extensive left para-aortic metastatic mass (A). Three months following radiotherapy much of the contrast medium has disappeared but the extent of the mass is unaltered (B).

\section{Prostatic Tumours}

The importance of lymphatic metastases from carcinoma of the prostate has tended to be underestimated in the past. An appreciable number of such patients have lymph node deposits, which are clinically undetectable, at a time when no bony deposits are present. Flocks (1963) found nodal metastases in $40 \%$ of patients with extraprostatic extension of the tumour and in $8 \%$ of those without such extension. The commonest sites of such deposits are the internal iliac, obturator and common iliac nodes, but metastases may also occur in para-aortic and tracheobronchial nodes. Lymphatic metastases are not responsive to hormone therapy and, therefore, must be treated by other means. Flocks advises radical prostatectomy with pelvic node dissection in all cases considered operable, and lymphography is of obvious value in such a procedure.

\section{Penile Tumours}

The lymph drainage of the penis is to the superficial and deep inguinal nodes and to the iliac chains. The usual treatment of penile tumours is amputation of the penis with block dissection of the inguinal, obturator and iliac nodes in those cases where metastases are present (Buddington, Kickham and Smith, 1963). Lymphography may demonstrate deposits in clinically impalpable nodes and, conversely, may show that palpably enlarged nodes are inflammatory and not neoplastic. It may, therefore, give information of value in deciding 


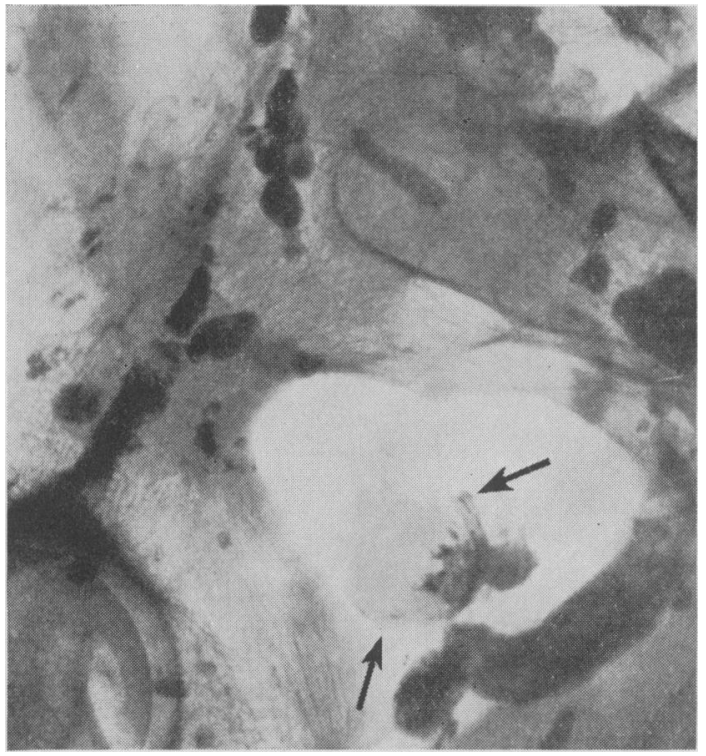

FIG. 12.-Bladder tumour. The lymphogram shows a left external iliac node with a peripheral filling defect and partial outlining of the periphery of a metastatic deposit (Arrows).

whether block dissection is necessary or not and will provide radiographic control of the procedure if dissection is carried out.

\section{Intralymphatic Radiotherapy}

The advantages of intralymphatic radiotherapy using ${ }^{131} \mathrm{I}$ lipiodol are still being assessed (Seitzman, Wright, Halaby and Freeman, 1963). Zeidman, Copeland and Warren (1955) have shown that there is no circulation of lymph through a metastatic deposit in a node. Since ${ }^{131}$ I produces shortly penetrating beta radiation it must come into intimate contact with the individual malignant cells in order to be effective. It will be of value, therefore, against solitary, viable malignant cells and possibly to some extent against microscopic deposits, but will have little effect against established metastases. When injected at the foot external scanning methods have demonstrated that it is retained in the inguinal, pelvic, para-aortic and left supraclavicular nodes. Since the lipiodol is filtered off in the lungs there is a danger that these organs will receive a significant amount of radiation. Seitzman and his colleagues (1963) have claimed that by stopping the injection when the contrast reaches the thoracic duct, or if any evidence of lymphatic obstruction is seen, this danger can be avoided, and that there is no measurable uptake by the liver, spleen, kidneys or thyroid. No systemic reaction is produced and there is no effect on hæmopoiesis. On the other hand, Koehler and his associates (1964) found, in experiments on dogs, that as much as $50 \%$ of the radioactive material was deposited in the lungs and that if the amount injected was reduced to avoid this, insufficient radiation was given to the nodes. It would seem that further work is necessary to assess accurately the risk of pulmonary damage in this technique. Nevertheless, it is an effective method of delivering radiotherapy to the lymphatic system. There is virtually no irradiation of tissues surrounding the nodes and general reactions do not occur. It would seem logical to use this technique in tumours of testis, penis, prostate, bladder and kidney prior to lymphadenectomy to avoid the dissemination of viable malignant cells during the operative procedure, and also so that any lymphatic tissue left behind will contain no such cells. It may be used in addition to external radiotherapy without increasing the dosage to surrounding tissues or the extent of any general reaction. The dosage to a node will be proportional to its uptake of contrast and the amount of radiation received by any node can, therefore, be assessed from plain films. Gough, Guiney and Kinmonth (1963) have reported encouraging results with intralymphatic ${ }^{138} \mathrm{Au}$ in the treatment of melanomata in which there was no clinical evidence of lymph node metastases. In the reticuloses lymph continues to circulate through the affected nodes, at any rate in the early stages, and, as would be expected, this technique has proved to be of considerable value (Chiappa, Galli and Severini, 1964).

\section{Chyluria}

Chyluria occurs as a result of an abnormal communication between the urinary and lymphatic systems. Such a communication is probably due to rupture of a lymphatic varix into the pelvis or calyces, the varix being formed as a result of chronic increased intralymphatic pressure. In the majority of cases chyluria is associated with filariasis and in areas in which this infestation is endemic the diagnosis presents little difficulty. Elsewhere, however, other causes must be excluded, such as thoracic duct obstruction from tumour or trauma, or congenital valvular incompetence of the lymphatics. Retrograde pyelography almost always shows pyelolymphatic reflux. On lymphography characteristic changes are demonstrated. The para-aortic lymphatics are 
August, $1965 \stackrel{\text { की }}{\frac{0}{0}}$

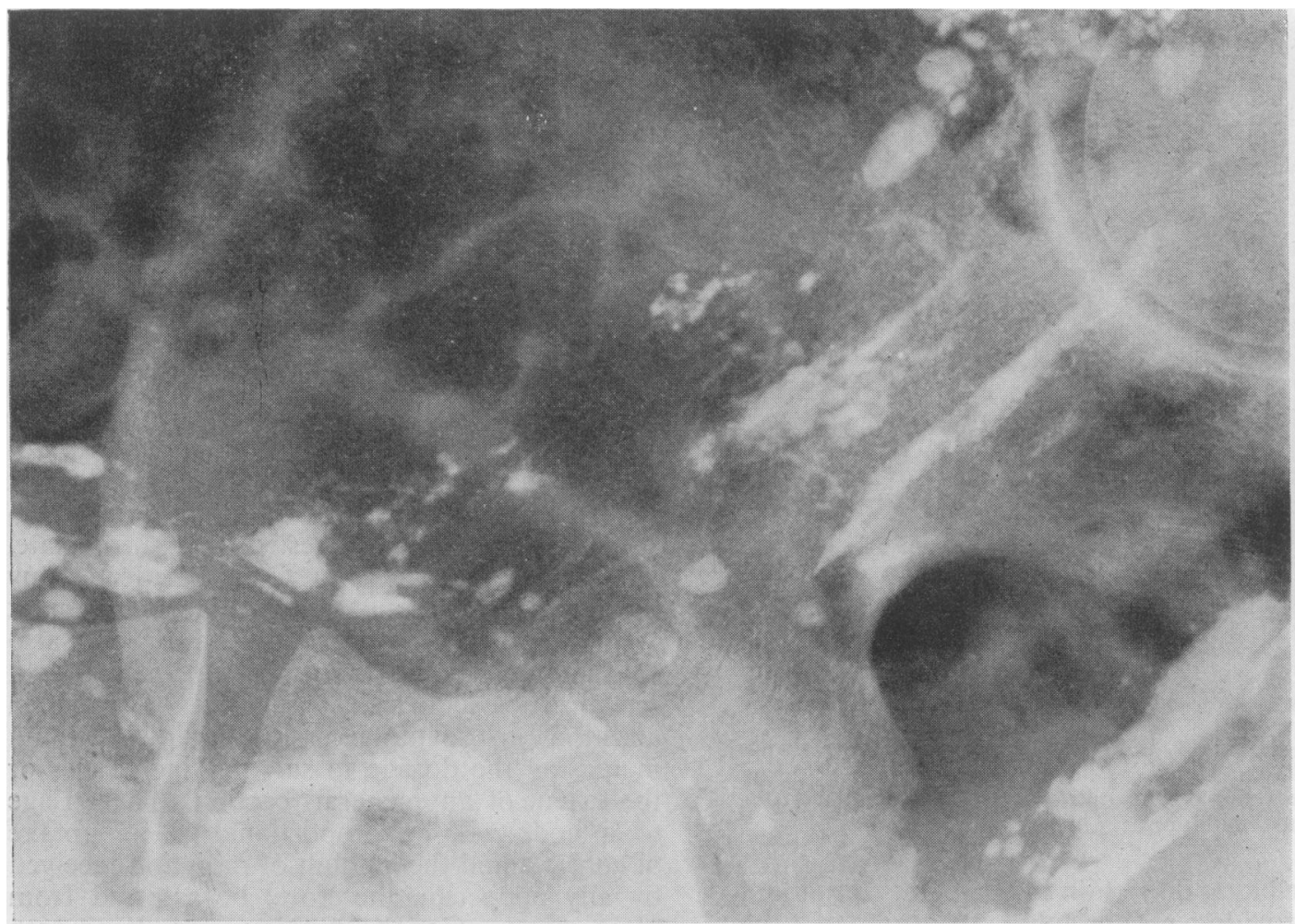




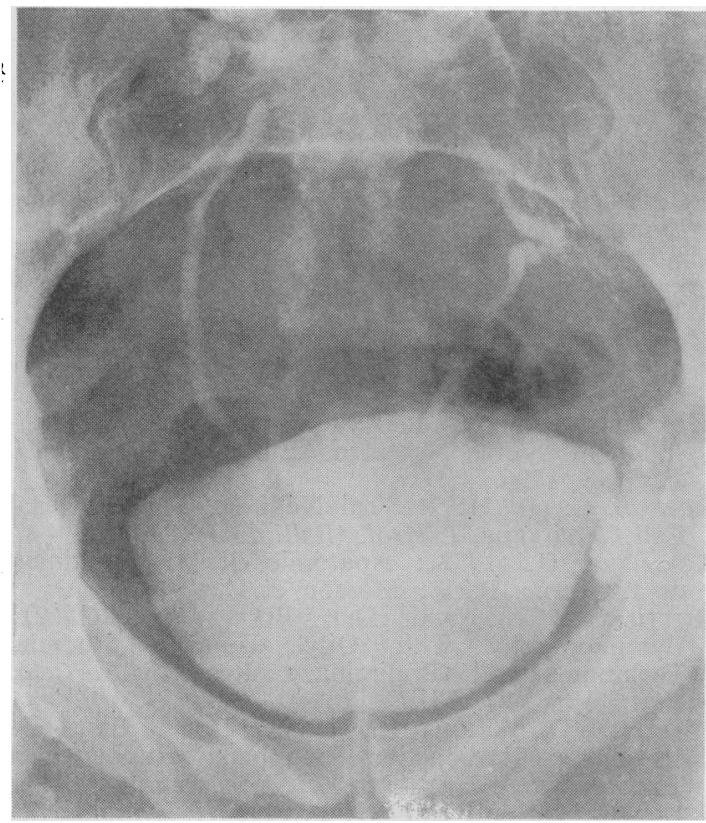

FIG. 14.-Carcinoma of the cervix. A lymphogram showed no ah urmality. Urograpy shows medial displacement of the left ureter by an internal iliac metastasis.

ectatic and tortuous, and multiple, abnormal vessels are seen passing from the lumbar chain to the kidneys. These vessels, which are seen only in chyluria, frequently reach the calyces, into which the lipiodol may pass, giving rise to a pyelogram. In the 24 -hour film few nodes are seen as a rule in the para-aortic region and those present frequently contain filling defects (Kishimoto, Higuchi, Endo and Kai, 1964). These appearances are in keeping with the work of Yamauchi (1945), who described cicatricial changes in the nodes and loss of elasticity in the lymph vessels in cases of chyluria (Swanson, 1963).

Treatment of this condition has in the past been unsatisfactory. Bed rest, by reducing the intralymphatic pressure, has produced temporary remissions, and chyluria can always be reduced by restriction of dietary fats. The instillation of sclerosing agents, such as silver nitrate or sodium iodide, into the renal pelvis seldom gives lasting benefit. Recently, however, excision of all lymphatic structures in the renal pedicle has proved a highly successful method of treatment, and in such a procedure one would expect lymphography to be of value in demonstrating the number and position of those vessels whose interruption is necessary. It can also be carried out following surgery to

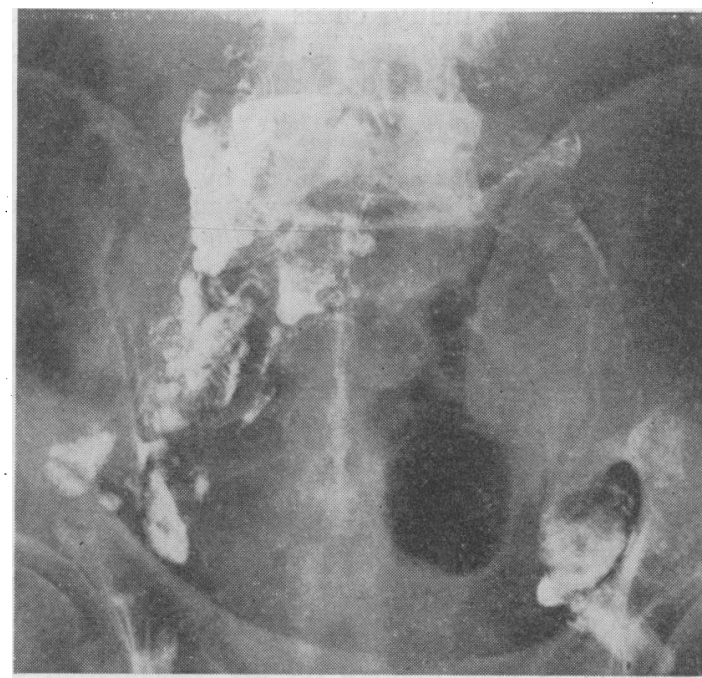

FIG. 15.-This patient presented with a left iliac fossa mass, of unknown aetiology. Barium enema and urography were negative. The lymphogram shows scanty contrast filling of a left pelvic mass with, elsewhere, nodal changes typical of Hodgkin's disease.

show the completeness of the operation. Cockett and Goodwin (1962) treated a case by anastomosis of a large lymphatic to the spermatic vein but the effect of this procedure could not be assessed since the remainder of the abnormal lymphatics were excised and a successful outcome may have been due to this.

\section{Retroperitoneal Fibrosis}

Clouse, Fraley and Litwin (1964) have reported on the lymphographic appearances in three cases of retroperitoneal fibrosis. They found non-filling of lymph vessels above the level of the 4th lumbar vertebra, stasis and dilatation of vessels below this, and extensive filling of hypogastric, presacral and peritoneal collaterals. They claim that a diagnosis can be made lymphographically before the characteristic ureteric abnormalities can be detected by urography or retrograde pyelography. These lymphographic appearances are not specific for retroperitoneal fibrosis but should raise the suspicion of this condition.

\section{Abdominal or Pelvic Masses}

Lymphography may be of value in the investigation of abdominal or pelvic masses of unknown aetiology. These may produce displacement or obstruction of a ureter or kidney, possibly with resulting hydronephrosis. It will determine whether such a mass is lymphatic in 
origin and in many cases will indicate the nature of the pathology (Fig. 15). Carcinomatous metastases and reticuloses may present in this way.

Figures 6 and 9 are reproduced by permission of the British Journal of Radiology, figures 1B, 5 and 12 by permission of the Journal of the Royal College of Surgeons of Edinburgh.

\section{REFERENCES}

BAUm, S., Bron, K., Wexler, L., and Abranis, H. (1963): Lymphangiography, Cavography and Urography, Radiology, 81, 207.

BENNET, H., and SHIVAS, A. (1954): The Visualisation of Lymph Nodes and Vessels by Ethyl Iodostearate (Angiopac) and its Effect on Lymphoid Tissue, J. Fac. Radiol. (Lond.), 5, 261.

Bron, K., BAUM, S., and ABRAMS, H. (1963): Oil Embolism in Lymphangiography, Radiology, 80, 194.

BRUUN, S., and ENGESET, A. (1956): Lymphadenography: A New Method for the Visualisation of Enlarged Lymph Nodes and Lymphatic Vessels, Acta radiol. (Stockh.), 45, 389.

BuDDINGTON, W., KICKHAM; C., and SMITH, W. (1963): An Assessment of Malignant Disease of the Penis, J. Urol: (Baltimore), 89, 442.

Chiappa, S., Galli, G., and Severini, A. (1964): Lymphadenography with Radioactive Contrast Medium in Retroperitoneal Localisation of Malignant Lymphogranuloma, Amer. J. Roentgenol., 92, 134.

Clouse, M., Fraley, E., and Litwin, S. (1964): Lymphangiographic Criteria for Diagnosis of Retroperitoneal Fibrosis, Radiology, 83, 1.

COCKETT; A., and GoodWIN, W. (1962): Chyluria: Attempted Surgical Treatment by LymphaticVenous Anastomosis, J. Urol. (Baltimore), 88, 566.

Desprez-Curely, J., Bismuth, V., Laugier, A., and DESCAMPS, J. (1962): Accidents and Complications of Lymphography, Ann. Radiol., 7-8, 577.

Flocks, R. (1963): Combination Therapy for Localised Prostatic Cancer, J.,Urol. (Baltimore), 89, 889.

Goúgh, M., GuineY, E., and KinMonTH, J. (1963): Lymphangiography: New Techniques and Uses, Brit. med. J., i, 1181 .

Herman, P., Benninghoff, D., Nelson, J., and MelliNs, H. (1963): Roentgen Anatomy of the Ilio-Pelvic-Aortic Lymphatic System, Radiology, $80,182$.

JACOBSSON, S., and JohansSON, S. (1959): Normal Roentgen Anatomy of the Lymph Vessels of Upper and Lower Exremities, Acta radiol. (Stockh.), 51, 321.

Kendall, B., Arthur, J., and Patey, D. (1963): Lymphangiography in Carcinoma of the Breast, Cancer, 16, 1233.
KinMONTH, J. B. (1952): Lymphangiography in Man : Method of Outlining Trunks at Operation, Clin. Sci., 11, 13.

KISHImoto, T., Higuchi, T., ENDo, M., and KaI, Y. (1964): Lymphography in a Patient with Unilateral Chyluria, J. Urol. (Baltimore), 92, 574.

Koehler, P., Meyers, W., Skelley, J., and Schaffer, B. (1964): Body Distribution of Ethiodol Following Lymphangiography, Radiology, 82, 866.

MACDONALD, J., and WALLACE, E. (1965): Lymphangiography in Tumours of Kidney, Bladder and Testicle, Brit. J. Radiol., 38, 93.

MAHAFFY, R. (1964): A Comparison of the Diagnostic Accuracy of Lymphography, Cavography and Pelvic Venography, Brit. J. Radiol., 37, 422.

MENVLLE, L., and ANE, J. (1932): Roentgen Visualisation of Lymph Nodes in Animals, J. Amer. med. Ass., 98, 1796.

ROBSON, C. (1963): Radical Nephrectomy for Renal Cell Carcinoma, J. Urol. (Baltimore), 89, 37.

Rouviere, H. (1932): Anatomie des Lymphatiques de l'Homme, Paris: Masson et Cie.

RuttimanN, A., and DeL BuONo, M. (1962): Lymphography with Oily Contrast Medium. Technique and Preliminary Results, Fortschr. Röntgenstr., 97, 551.

Seitzman, D., Wright, R., Halaby, F., and Freeman, J. (1963): Radioactive Lymphangiography as a Therapeutic Adjunct, Amer. J. Roentgenol., 89, 140.

SeITZMAN, D., and HALABY, F. (1964): Lymphangiography: An Evaluation, J. Urol. (Baltimore), 91, 301 .

SMITHERS, D., and WALlaCe, E. (1962): Radiotherap年 in the Treatment of Patients with Seminomas and Teratomas of the Testicle, Brit. J. Urol., 34, 422.

Swanson; G. (1963): Lymphangiography in Chylurises Radiology, 81, 473.

Tavel, F., Osius, T., Parker, J., Goodfriend, R., MCGONIGLE, D.,' JASSIE, M., SIMMONS, E., ò Tobenkin, M., and SCHUlte, J. (1963): Retroperitoneal Lymph Node Dissection, J. Urol. (Baltimore), 89, 241.

Wallace, S., JACKSON, L., Schaffer, B., Gould, J., GREENING, R., WeISS, A., and KRAMER, S. (1961): Lymphangiograms: Their Diagnostic and Therapeutic Potential, Radiology, 76, 179.

WHITESEL, J. (1964): Lymphography: Its Place in Urology, $J$. Urol. (Baltimore), 91, 613.

WhitMore, W., and MARShall, V. (1962): Radical Total Cystectomy for Cancer of the Bladder: 230 Consecutive Cases 5 Years Later, J. Urol. (Baltimore), 87, 853.

Yamauchi, S. (1945): Chyluria; Clinical, Laboratory and Statistical Study of 45 Personal Cases Observed in Hawaii, J. Urol. (Baltimore), 54, 318.

ZEIDMAN, I., COPELAND, B., and WARREN, S. (1955): Experimental Studies on Spread of Cancer in Lymphatic System; Absence of Lymphatic Supply ơ in Carcinoma, Cancer, 8, 123. 